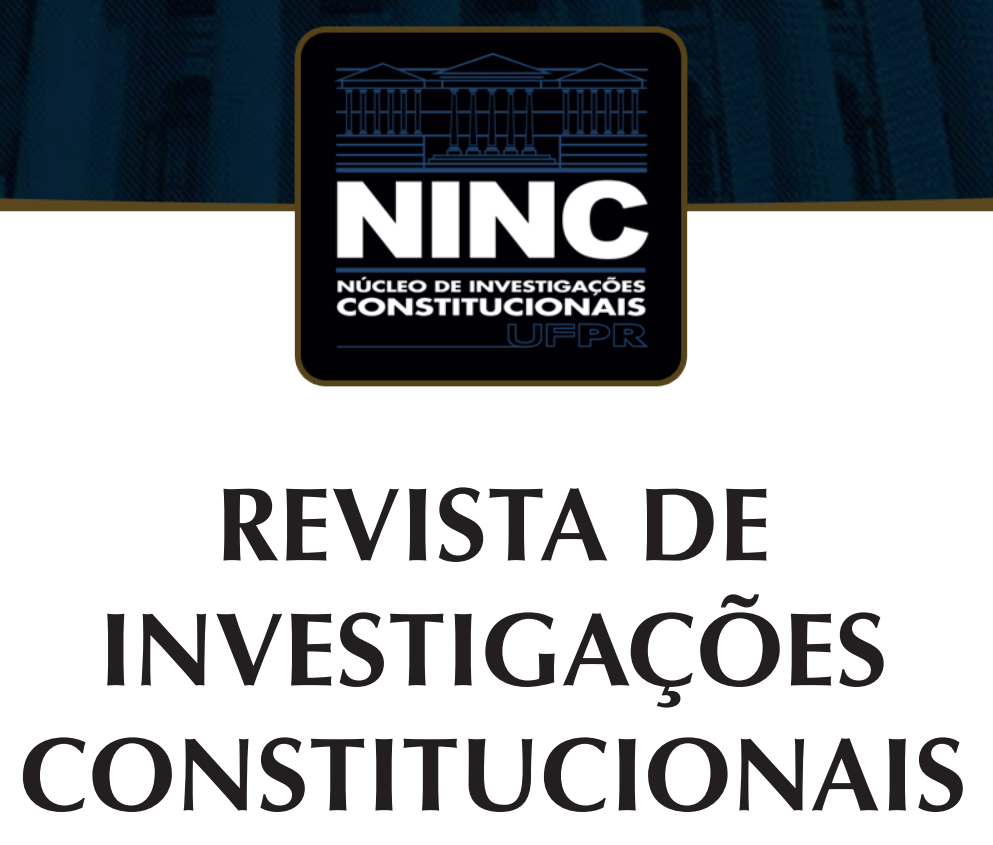

JOURNAL OF CONSTITUTIONAL RESEARCH

vol. 6 | n. 3 | setembro/dezembro 2019 | ISSN 2359-5639 | Periodicidade quadrimestral Curitiba | Núcleo de Investigações Constitucionais da UFPR | www.ninc.com.br 


\title{
La educación como derecho social, humano y fundamental: principios y perspectivas de la educación moderna
}

\section{Education as a social, human and fundamental law: principles and perspectives of modern education}

\author{
PABLO JIMÉNEZ ${ }^{1}$ * \\ 'Centro Universitário Salesiano de São Paulo (São Paulo-SP, Brasil) \\ metodologo2001@yahoo.com.br \\ https://orcid.org/0000-0001-9254-9161
}

Recebido/Received: 20.02 .2018 / February $20^{\text {th }}, 2018$ Aprovado/Approved: $16.11 .2019 /$ November $16^{\text {th }}, 2019$

Resumen

En el presente artículo se discute el significado del Derecho a la Educación en la sociedad contemporánea. Se define la Educación como un conjunto de actividades (o procesos) que objetivan la formación del ser humano $y_{\text {, }}$ fundamentalmente, como un Derecho humano, fundamental y social consagrado en la Constitución Federal Brasileña. Se trata, pues, la problemática que envuelve la concepción tradicional de la Educación y sus limitaciones teóricas y prácticas para la resolución de los problemas sociales, jurídicos y morales presentes en las sociedades contemporáneas.

Palavras-claves: educación; derecho social; derecho humano; derecho fundamental; perspectivas.
Abstract

This article discusses the meaning of the right to education in contemporary society. Education is defined as a set of activities (or processes) that aim the formation of the human being and, fundamentally, as a human, fundamental and social right enshrined in the Brazilian Federal Constitution. Therefore, we approach a problem that involves the traditional conception of education and its theoretical and practical limits in the resolution of social, legal and moral problems present in contemporary societies.
Keywords: education; social right; human right; fundamental right; perspectives.

Como citar esse artigo/How to cite this article: JIMÉNEZ, Pablo. La educación como derecho social, humano y fundamental: principios y perspectivas de la educación moderna. Revista de Investigações Constitucionais, Curitiba, vol. 6, n. 3, p. 669-686, set./dez. 2019. DOI: 10.5380/rinc.v6i3.58017.

" Professor e pesquisador do Programa de Mestrado em Direito do Centro Universitário Salesiano de São Paulo- UNISAL (São Paulo-SP, Brasil). Doutor em Direito pela Faculdade de Direito da Universidade do Oriente, Cuba. Professor do Centro Universitário de Volta Redonda - UniFOA. Professor do Centro Universitário de Barra Mansa - UBM. E-mail: metodologo2001@yahoo.com.br. 


\section{SUMARIO}

1. Introducción; 2. La educación como ciencia; 3. La educación como proceso; 3.1. Educación formal; 3.2. Educación informal; 4. La educación como derecho; 5 . Las razones de la educación; $\mathbf{6}$. Objetivos de la educación moderna; 7. Principios de la educación moderna; 8. Conclusión; 9 . Referencias.

\section{INTRODUCCIÓN}

La Educación es, frecuentemente, definida como el arte de enseñar o de instruir, esto es, un conjunto de actividades que objetivan el desarrollo de la capacidad física e intelectual del ser humano.

Ciertamente, el concepto "Educación" se ha usado en distintos sentidos, designándose, mayormente, el conjunto de influencias que la naturaleza y el proprio hombre ejercen sobre la inteligencia o la voluntad humana o todo lo que hacemos por cuenta propia con el objetivo de aproximarse a la perfección de nuestra naturaleza. ${ }^{1}$

Mas, definir la Educación no es tarea fácil. Para ensayar una definición que se diga oportuna o moderna es preciso considerar todos los sistemas o modelos educacionales conocidos, para luego, derivar, a partir de un estudio comparativo, sus aspectos comunes. Solamente una investigación histórico-comparada nos permitiría llegar a una definición común.

En la Pedagogía moderna, por ejemplo, existe un esfuerzo en correlacionar los conceptos educar y enseñar, siendo que este último puede corresponderse a la organización de las condiciones exteriores propias al aprendizaje. Ciertamente, esas condiciones deben ser proyectadas de manera gradual, llevándose en cuenta, en cada etapa, las habilidades adquiridas, la necesidad de retención de esas habilidades y la situación estimuladora específica exigida por la etapa siguiente. Consecuentemente, educar y enseñar son actividades bastante complejas y arduas. $^{2}$

Nótese que educar, enseñar, instruir, dar clases "en cualquier nivel" y adiestrar son términos usados, con mucha frecuencia, en el mismo sentido, al indicar el proceso de iniciación al conocimiento. Así, el profesor que enseña tiene como objetivo garantizar que cada estudiante, de forma independiente, sea capaz de observar, analizar y pensar críticamente. En esa perspectiva, el profesor, ahora colocado como único gestor, ayuda a localizar nuevas informaciones, a interpretar, a resumir las ideas esenciales de los textos y a vincular los problemas teóricos a los principios, reglas y a los ejemplos de la vida diaria.

DURKHEIM, Émile. Educação e Sociología. Trad. de Stephania Matousek. 3. ed. Petrópolis, RJ: Vozes, 2012, p. 43.

2 GAGNÉ, Robert. Como se realiza a aprendizagem. Trad. Thereziña Maria Ramos Tovar. Rio de Janeiro: Livros Técnicos e Científicos Editora S. A / MEC, p. 22. 
Pero, esa no es la definición que estamos procurando. Ella tal vez sea un significado más apropiada para la llamada enseñanza (o educación formal), directa o escolar, donde se pone a la escuela como el lugar principal del aprendizaje. Se trata, pues, de una definición incompleta e inapropiada para lo que, a seguir, iremos a considerar como Educación, aquella que, también, se desarrolla más allá de la instrucción escolar.

Dicho esto, definimos la Educación como un conjunto de acciones esenciales para la edificación del individuo en aras a la convivencia social. Esta es nuestra definición: la Educación consiste en un conjunto de procedimientos, decisiones y acciones que, provenientes de la convivencia familiar, escolar y social, objetivan la edificación de aquel ser humano que la propia sociedad desea.

\section{LA EDUCACIÓN COMO CIENCIA}

La Educación puede ser considerada una "ciencia" constitutiva de un conjunto de teorías, métodos y técnicas que objetivan la edificación del hombre, principalmente de los jóvenes: niños y adolescentes.

Cualquier estudio sobre el carácter científico de la "Educación" ha de considerar sus métodos, objeto y finalidades (objetivos), investigación compleja por existir innumerables pedagogías que tienen como propósito perfeccionar el proceso de enseñanza-aprendizaje en sus diferentes etapas. Es que, si, por un lado, la diversidad de teorías es positiva, por otro las críticas, cuando son posibles, no tienen como objeto el marco teórico-cualitativo (pedagógico), más ciertamente la ausencia de propuestas que orienten la Educación en valores.

De cualquier manera, la noción cientificista de la Educación es completamente clara, cuando se piensa en el importante papel que ella desempeña. Ciertamente que la Educación "no se confunde ni con la actividad efectiva del educador, ni mismo con la Pedagogía, que objetiva dirigir esta actividad"3. Si ser y conducta son su objeto, educar es su objetivo.

Por otro lado, se confunde, con frecuencia, la "Educación" con la "Pedagogía". Pero, tales conceptos también deben ser diferenciados. Veamos que, si por un lado la Educación es el conjunto de acciones ejercidas por la familia, la sociedad y la escuela; por otro, la Pedagogía es el conjunto de teorías que explican la mejor forma de concebir y desarrollar la Educación. Concordante o no con las prácticas, las teorías pedagógicas procuran explicar y sistematizar el desarrollo de las acciones educacionales, presentándose, Así, como un conjunto de conocimientos ordenados acerca de esas realidades o prácticas.

3 DURKHEIM, Émile. Educação e Sociología. Trad. de Stephania Matousek. 3. ed. Petrópolis, RJ: Vozes, 2012, p. 17. 
La Educación, ahora definida como ciencia puede ser considerada como el conocimiento o conjunto de conocimientos desarrollados en esa importante área del saber humano.

\section{LA EDUCACIÓN COMO PROCESO}

La Educación puede ser definida como un proceso por medio del cual las personas son preparadas para la vida en convivencia con otras personas. Es, pues, por medio de la Educación que el ser humano desarrolla sus capacidades morales e intelectuales. Así las personas son orientadas a utilizar bien sus potencialidades en beneficio de todos.

La Educación es un "proceso de reconstrucción y reorganización de la experiencia, por el cual le percibimos más agudamente su sentido, y con eso nos habilitamos a dirigir mejor el curso de nuestras experiencias futuras". ${ }^{4}$ Al ser definida como un proceso la Educación, nos enseña Cunningham, ha de ser encarada a partir de dos puntos de vista, por ejemplo, individual y, también, social. ${ }^{5}$

Como proceso, se nota la Educación como un conjunto de acciones o procedimientos convencionales (planeados) y no convencionales (espontáneos). Como explicaremos, a seguir, la educación convencional o planeada puede ser definida como "formal". Ya la no convencional o espontánea será denominada como "educación informal". Obsérvese que tanto la educación formal como la informal influyen decisivamente en la formación de los jóvenes, fomentando el desarrollo del individuo y de la sociedad. Por tanto, no se puede decir que una sea más importante que la otra, pues en realidad ambas pueden sufrir influencias decisivas en la vida de cualquier persona. ${ }^{6}$ Veamos.

\subsection{Educación formal}

Definimos la educación formal, como aquella que se atiene a los métodos y a las fórmulas preestablecidas (convencionales) y que se desarrolla de forma organizada y consciente, donde siempre participa un agente que tiene la intención de enseñar y otro que objetiva aprender. El ejemplo más claro de ese tipo de educación es la escolar, aquella que se inicia en la escuela como institución y no únicamente en la clase.

Es fundamentalmente la escuela el espacio donde se desarrolla ese proceso de enseñanza-aprendizaje. Este es considerado como un proceso integrado y cualitativo por el cual la persona se torna más bien preparada para nuevos aprendizajes. No se

DEWEY, John. Vida e Educação. 10. ed. São Paulo: Melhoramentos, 1978, p. 17.

5 CUNNINGHAM, Willian Francis. Introdução à Educação: Problemas fundamentais, finalidades e técnicas. 2. ed. Porto Alegre: Globo, 1975, p.5.

6 DALLARI, Dalmo de Abreu. Direitos humanos e Ciudadania. São Paulo: Moderna, 1998, p. 48. 
trata, pues, de un aumento cuantitativo de conocimientos, pero sí de una transformación estructural de la inteligencia y de la edificación moral de la persona. ${ }^{7}$

De hecho, el proceso de la educación formal envuelve diversos factores, entre los cuales se destacan los sujetos activos: el gestor (director, funcionario o profesor) y el educando. Se trata de un proceso que ha de poner la escuela en primer lugar como Vida y no como preparación para la vida.

De ese modo, el proceso de educación formal recorre esencialmente a la consolidación de la correlación entre la formación integral del pupilo como ser individual y social, lo que exige la integración de la docencia con la actividad de investigación y con la práctica. Sólo con un proceso educativo que sea capaz de garantizar esta integración; es que será posible formar profesionales aptos para confrontar los desafíos de un presente complejo y de un futuro de competitividad a nivel mundial.

Lógicamente, que la educación formal también se vincula a factores que son decisivos para la formación integral de los estudiantes, o sea, factores que acontecen en la vida familiar, en la sociedad y en la práctica diaria. Respetando el principio de la garantía del patrón de calidad de ese tipo de educación, el proceso debe ser desarrollado objetivando la formación de un hombre nuevo, íntegro y creativo.

Así, como principales características de la educación formal podemos apuntar: a) la imparcialidad; b) la independencia e; c) la transparencia. Decimos entonces que la educación formal tiene como base el aprendizaje y el ejemplo. En ese proceso se torna viable el conocimiento y el desarrollo de un pensamiento científico-crítico y moral. Quien aprende, así, irá acumulando cultura, siendo que, el volumen de lo que se enseña sirve de base para la comprensión de nuevas experiencias. Por tanto, los resultados de las acciones desarrolladas en la educación formal no se reducen únicamente a los conocimientos obtenidos por una prueba escrita, pues el proceso es mucho más que eso.

Podemos concluir que la educación formal se torna cada vez más eficiente cuando prioriza: a) el desarrollo de la capacidad (habilidades) científico-crítica; b) el estímulo al trabajo en grupo (cooperación, colaboración, colegimos) e; c) la edificación de una conciencia jurídica y moral, con base en los principios, normas y valores generales de la sociedad.

\subsection{Educación informal}

Definimos la educación informal como aquel proceso no planeado y espontáneo que se desarrolla lejos de la escuela, pero que repercute, de hecho, en la formación del ser humano. Considerarnos que la educación informal se desarrolla en el seno familiar y en el medio social donde los jóvenes conviven.

7 DÍAZ Bordenave, Juan e Martins Pereira, Adair. Estratégias do ensino aprendizagem. 14. ed. Petrópolis: Vozes, [s.d.], p 25. 
En una acepción más alargada, ese tipo de educación también comprende los efectos indirectos producidos en el carácter y en las facultades del hombre por cosas cuyo objetivo puede ser completamente diferente: leyes, formas de gobierno, artes, deporte, propaganda (publicidad), influencias naturales, tales como el clima, el suelo y la posición local ${ }^{8}$, cuya influencia puede ser negativa o positiva.

Cuando la influencia de la educación informal es significativamente negativa, se pone en riesgo todo el proyecto escolar, constituyéndose tal influencia en una fuente de desorientación y desvío de la conducta juvenil y de la anti-conciencia.

Se da como ejemplo negativo el hecho del mercado de consumo estar adaptado a la educación o sea a una "cultura de casino" líquido-moderna, la cual, por su vez, está adaptada a las presiones y seducciones de ese mercado. Las dos se armonizan bien y se alimentan mutuamente. Los mercados de consumo ofrecen productos destinados al pronto consumo, de preferencia de una única vez. Los clientes, confusos delante de la asombrosa variedad de ofertas (propaganda muchas veces abusivas y engañosas) y del ritmo vertiginoso con que ellas cambian, no pueden más confiar en la facilidad de aprender y memorizar; así deben aceptar. Observase, un daño perjudicial al ponerse la educación a merced de los mercados de consumo. Luego, nótese que el problema de los jóvenes está siendo considerado claro y explícitamente una cuestión de adiéstralo para el consumo. ${ }^{9}$

Mas, cuando el proceso de formación y orientación de jóvenes ocurre favorablemente, el propio estudiante valoriza su papel y la posición que poco a poco pasa a ocupar en la sociedad.

De hecho, el joven necesariamente participa de esa convivencia social y en él se nutre de sus valores. En otras palabras, la educación informal conduce y condiciona el desarrollo del individuo y de la sociedad en general. "Se puede conceptuar, en este particular, la educación como el proceso de actuación sobre el individuo a fin de llevarlo a un estado de madurez que lo capacite a encontrarse con la realidad de manera consciente, equilibrada y eficiente, y en ella actuar como ciudadano participante y responsable".10

Resumiendo, la Educación ha de ser considerada en dos sentidos: formal e informal. La educación formal se manifiesta por medio del vínculo escuela-alumno, donde prima la voluntad de educar con base en métodos de enseñanza preconcebidos y convencionales. A su vez, la informal ocurre independientemente de ese vínculo, y en ella desempeñan papeles importantes la familia, la comunidad, los medios de

8 DURKHEIM, Émile. Educação e Sociología. Trad. de Stephania Matousek. 3. ed. Petrópolis, RJ: Vozes, 2012, p. 43.

9 BAUMAN, Zygmunt. Sobre Educação e juventude: conversas com Ricardo Mazzeo. Trad. Carlos Alberto Medeiros. Rio de Janeiro: Zahar, 2013, p. 37, 50, 53.

10 GIUSEPPE Imídeo Nérici. Metodologia do ensino. Uma introdução. 4. ed. São Paulo: ATLAS, 1992, p 15. 
comunicación de masa, tales como radio, televisión, cine, prensa escrita, y comunidad dónde el propio hombre se desarrolla, etc.

\section{LA EDUCACIÓN COMO DERECHO}

La “Educación”, desde el punto de vista jurídico, se conceptúa como un Derecho superior y esencial a la convivencia humana. Se trata, pues, de un Derecho venerable de todo ser humano, por ser causa y condición del desarrollo pleno de las capacidades física, intelectual y moral del hombre. Por ese motivo existe la obligación de ser respetada por todos, pues es en esa obligación que reside el proprio fundamento jurídico y moral de la Educación.

Es posible considerar la Educación como un "supra Derecho" (o sobre Derecho), pues, por medio de ella, ha de garantizarse la concretización de aquellas acciones moralmente necesarias a la realización de la Ciudadanía. Es, por medio del Derecho a la Educación, que los demás Derechos serán reconocidos y concretizados.

En verdad, la Educación es un Derecho que se deriva del derecho de la personalidad y del principio de la Dignidad humana. Es un derecho fundamental y necesario a la ciudadanía, así previsto art. 205 de la Constitución Federal: un Derecho de todos, y un deber del Estado. ${ }^{11}$ Se trata de un Derecho humano (de segunda generación o dimensión), fundamental y social, de orden pública y de interés general, felizmente, consagrado en un conjunto de normas y dispositivos, que, como estudiaremos en el capítulo 4, que forman parte de los ordenamientos jurídicos internacional y nacional: un Derecho humano que, como decimos, condiciona la edificación de la conciencia y la concretización de la Dignidad, del orden y de la justicia social.

Igualmente, el Derecho a la Educación puede ser dicho de premisa y condición de los demás Derechos y garantías fundamentales consagrados en el artículo $5^{\circ}$ de la Constitución Federal, dispositivo donde se prescriben: la libertad de pensamiento, conciencia, el acceso a la información, etc. Vemos, igualmente, la Educación como un Derecho social, también, previsto en el artículo $6^{\circ}$ de la propia Constitución Federal, prescripción que autoriza a exigir del Estado prestaciones positivas y materiales para la garantía del cumplimiento de ese Derecho. ${ }^{12}$

La Educación, por ser un Derecho humano, fundamental y social ha de ser concebida como un Derecho de todos y para todos. Esta es una premisa de la cual partiremos

\footnotetext{
11 Art. 205.. La educación, derecho de todos y deber del Estado y de la familia, será promovida e incentivada con la colaboración de la sociedad, tendiendo al pleno desarrollo de la persona, a su preparación para el ejercicio de la ciudadanía y a su calificación para el trabajo.

12 Art. $6^{\circ}$ Son derechos sociales la educación, la salud, la alimentación, el trabajo, la vivienda, el transporte, el descanso, la seguridad, la previsión social, la proyección de la maternidad y la infancia, la asistencia a los desamparados, en la forma de esta Constitución.
} 
para afirmar la responsabilidad universal, asunto que, también, será objeto de discusión en la presente obra.

Se observa, así, que las tareas de educar es deber de todos: del Estado (de los gobiernos), de la comunidad, de las instituciones públicas y privadas (escuelas, asociaciones, iglesias, sociedad) y, principalmente, de las familias: todos inspirados en el principio de libertad y en los ideales de la solidaridad humana, que tienen por finalidad el pleno desarrollo del educando, su preparación para el ejercicio de la Ciudadanía y su calificación para el trabajo. ${ }^{13}$

En esta perspectiva, el Derecho a la Educación ya está en condiciones de ser considerado e introducido en los contenidos de las disciplinas universitarias como un microsistema de la ciencia jurídica, cuya tendencia es de ser sistematizado e integrado en teorías, principios y normas propias, derecho que objetiva estudiar y tutelar las relaciones jurídicas educacionales establecidas tanto en el contexto escolar, familiar y social.

Resumiendo, la Educación es un Derecho cuyo reconocimiento y concretización es la condición necesaria para el perfeccionamiento de la persona humana y para el desarrollo de la civilización. ${ }^{14}$ Promover la educación en valores es evitar la neutralidad de las ciencias, es posibilitar la concretización de la humanización social.

\section{LAS RAZONES DE LA EDUCACIÓN}

La Educación tiene un fin social, ella es "socializante", esto es, instrumental (o funcional): esa es su principal razón práctica.

Al respecto, enseña Émile Durkheim ${ }^{15}$, la Educación es cosa social: Eso quiere decir que ella pone al ser humano en contacto con una determinada sociedad. Diferentemente de cómo algunos filósofos y pedagogos la consideraran, ella no es eminentemente individual. Así, de acuerdo con nuestro autor, la Educación se define como una forma de socialización.

Y aquí se establece una debatida cuestión: al nacer, afirma Émile Durkheim, un niño trae apenas su naturaleza de individuo. Por tanto, al llegar a la vida cada ser humano se presenta para la sociedad en condición de una tabla casi rasa que necesita ser escrita. “Es preciso que, por los medios más rápidos, la sociedad sustituya al ser egoísta y asocial que acaba de nacer por otro capaz de llevar una vida moral y social. Esa es la

13 Ley 9.394, de 20 de diciembre de 1996 (Nueva Ley de Directrices y Bases de la Educación Nacional), arts. $1-2$.

14 BOBBIO, Norberto. A Era dos Direitos. Trad. Carlos Nelson Coutiño. Rio de Janeiro: Elsevier, 2004, p. 17.

15 DURKHEIM, Émile. Educação e Sociología. Trad. de Stephania Matousek. 3. ed. Petrópolis, RJ: Vozes, 2012, p. 13. [Para Kant, Mill y Herbart, Spencer, el objetivo de la Educación sería antes de todo realizar en cada individuo los atributos constitutivos de la especie humana en general, elevándolos a su más alto grado de perfección]. 
obra de la Educación"; pues, "por ser sociales, las características específicas que distinguen al hombre son transmitidas por una vida social: la Educación".16

Ese asunto enciende la discusión acerca de las verdades y de las incertidumbres del innatismo, aquella orientación por medio de la cual se afirman que al nacer ya traemos algún conocimiento, ideas o condición moral innata o si, por el contrario, al nacer estamos lejos de poder comprender lo que es moral, amoral o inmoral. Se trata de una discusión que por su complejidad y extensión no será objeto de estudio en el presente trabajo, mas que será objeto de otras obras relativas a la Filosofía moral y al Derecho.

Así, retornando a lo que nos interesa más aquí, la Educación ha de ser concebida como un instrumento para la edificación del ser humano. Así, ese sentido es concordante con sus características, por ejemplo, holística, edificadora y transformadora que, a seguir, pasaremos a estudiar.

a) Holística. Pues bien, cuando usamos la categoría "holística" queremos indicar que la Educación debe ser inclusiva y alcanzar a todos. Ella, como ya fue dicho, es de todos y para todos. En ese sentido, tiene como destinatario a todos los ciudadanos.

En este punto, consideramos conveniente discutir la necesidad de introducir una nueva concepción de Educación, teniendo como objetivos esenciales la inserción y realización del hombre en el contexto en que vive, importando la edificación de la conciencia: premisa para la concretización de los Derechos y de la Ciudadanía. Con esa intención es conveniente alertar acerca de la carencia de propuestas que orienten, concretamente, lo que se debe y como se debe enseñar.

b) Edificadora. La Educación ha de ser edificadora. Ella, más allá de la instrucción ha de edificar al ser humano.

Más allá de la instrucción, esto es, de la mera transmisión de conocimientos, concebimos la Educación como un proceso formativo que ha de objetivar también la preparación del hombre para la vida: una Educación que oriente la convivencia social, direccionando, así, la práctica de las buenas acciones.

c) Transformadora. Como consecuencia de la edificación surge su tercera característica y función: la transformación.

Tales son los atributos de la Educación que la humanidad espera. Se puede, con efecto, afirmar que la Educación holística (o inclusiva), primero "edifica" y, luego, "transforma".

La Educación, ya vimos, desarrolla las capacidades física, intelectual y moral del ser humano objetivando posibilitar la inserción social del hombre en el contexto donde vive. Así ella se convierte en un proceso necesario a la Ciudadanía y a la Dignidad del ser humano, siendo, en ese sentido, un Derecho del educando y un deber de la sociedad.

16 DURKHEIM, Émile. Educação e Sociología. Trad. de Stephania Matousek. 3. ed. Petrópolis, RJ: Vozes, 2012, p. 11. 


\section{OBJETIVOS DE LA EDUCACIÓN MODERNA}

La Educación, ahora definida como el conjunto de acciones, procedimientos, comportamientos y actitudes ejercidas en la convivencia familiar, escolar y social, tiene como objetivo suscitar y desarrollar en el ser humano, fundamentalmente en los niños y jóvenes, cierto número de estados físicos, intelectuales y morales exigidos tanto por la sociedad política como por el medio específico al cual ellas están destinadas en particular. ${ }^{17}$

Existe un único propósito invariable de la Educación, explica Bauman, es y continuará siendo la preparación de los jóvenes para la vida según las realidades que tendrán que enfrentar. Para estar preparados, ellos precisan de instrucción, esto es, de conocimiento práctico, concreto e inmediatamente aplicable y, para ser práctico, la enseñanza de calidad precisa promover y propagar un proceso de oclusión mental. Pero, ocurre que los jóvenes, actualmente, no están más incluidos en el discurso sobre la promesa de un futuro mejor. Al contrario, ahora son considerados parte de una población dispensable. Se piensa en la juventud y luego se presta atención a ella como un dato, como un mercado a ser modificado, penetrado y explorado, usándose la fuerza educacional de una cultura que comercializa todos los aspectos de la vida de niños y jóvenes. Sirviéndose del internet, de las varias redes sociales, y de las nuevas tecnologías de media, como teléfonos celulares, las instituciones empresariales buscan sumergir a los jóvenes en un mundo de consumo en masa, de manera más amplia y directa que cualquier cosa que podemos haber visto en el pasado. ${ }^{18}$

Surge, así, el siguiente dilema (problema): ¿la Pedagogía moderna (como conjunto de teorías y métodos) debe privilegiar el conocimiento lógico, fundado en proposiciones histórico-descriptivas que objetivan diseminar la información (la instrucción)? o ¿la construcción racional fundada en proposiciones valorativas y prescriptivas que, procurando lugares comunes, objetiven la edificación de una conciencia social, esto es, la razón del respeto, de la responsabilidad, de la prudencia etc.?

Cualquier respuesta que se diga coherente deberá estar correlacionada a los objetivos de la Educación y al tipo de Pedagogía (modelo) que la dinámica de la vida moderna nos impone: una Pedagogía edificadora o transformadora, pues, ciertamente, la Educación tradicional, aquella que torna predominante la instrucción y que, igualmente, es dominante en la América Latina, se muestra ineficaz para la edificación de la conciencia social.

17 DURKHEIM, Émile. Educação e Sociología. Trad. de Stephania Matousek. 3. ed. Petrópolis, RJ: Vozes, 2012, p. $10,15$.

18 BAUMAN, Zygmunt. Sobre Educação e juventude: conversas com Ricardo Mazzeo. Trad. Carlos Alberto Medeiros. Rio de Janeiro: Zahar, 2013. p. 25, 52. 
No es demás, por otro lado, afirmar que el concepto de Educación que únicamente insiste en el proceso de enseñanza-aprendizaje se tornó inútil, incapaz de contribuir para la concretización de la Ciudadanía y de los Derechos, especialmente, de los Derechos humanos y fundamentales que, como decimos, están felizmente consagrados en las constituciones latino-americanas.

Este es uno de los mayores pecados (o insuficiencias) de la Pedagogía moderna, aquella que está más preocupada con la formación de un profesional y no con la formación de un buen profesional. Ciertamente, si queremos un buen ciudadano, un buen político, un buen profesor, un buen médico, un buen abogado, etc. la concepción moderna de Educación deberá ser adaptada a las nuevas exigencias ante el aumento de la criminalidad, de la violencia juvenil, de la ilegalidad, de la inmoralidad y de los contravalores que se imponen a la organización social.

Decimos entonces que la Educación tiene como objetivo tornar al ser humano independiente, capaz de observar, analizar y pensar críticamente. Así, la Educación es condición esencial para el desarrollo "socio individual", esto es, del ser "individual" y del ser "social". En este sentido, afirma DURKHEIM"19, la Educación ha de ser concebida así:

Porque en cada uno de nosotros, se puede decir, existen dos seres que, independientemente de que se muestren inseparables - a no ser por abstracción -, no dejan de ser distintos. Uno es compuesto de todos los estados mentales que dicen respecto apenas a nosotros mismos y a los acontecimientos de nuestra vida personal: el yo se podría llamar de ser individual. El otro es un sistema de ideas, sentimientos y hábitos que exprimen en nosotros no la personalidad, pero si el grupo o los grupos diferentes de los cuales formamos parte tales como las creencias religiosas, las creencias y prácticas morales, las tradiciones nacionales o profesionales y las opiniones colectivas de todo tipo. Este conjunto forma el ser social. Constituir este ser en cada uno de nosotros es el objetivo de la Educación.

Resumiendo, la Educación tiene como objetivo principal socializar y posibilitar la inserción del ser humano en el contexto en que vive.

\section{PRINCIPIOS DE LA EDUCACIÓN MODERNA}

Para pensar mejor los principios que han de orientar la Educación moderna precisamos retomar sus objetivos o propósitos, esto es, el telos ${ }^{20}$, del cual hablamos en el artículo anterior.

Pues bien, de acuerdo a su teleología la Educación contemporánea (o moderna) ha de ser concebida como instrumento que permite el desarrollo del ser humano.

\footnotetext{
19 DURKHEIM, Émile. Educação e Sociología. Trad. de Stephania Matousek. 3. ed. Petrópolis, RJ: Vozes, 2012, p. 10-11.

20 Télos, palabra griega que significa propósito, finalidad u objetivo (teleología).
} 
Importa, así, observar que la Educación, como explica Araña ${ }^{21}$ no debe ser vista como la simple transmisión de la herencia de los antepasados, mas como aquella por medio de la cual mantienen viva la memoria de un pueblo y da condiciones para su sobrevivencia. Se trata de una instancia mediadora que torna posible la reciprocidad entre individuo y sociedad.

Nos resta todavía tratar del modelo de principios que organizan la Educación moderna, por ejemplo, a) Justicia; b) Integridad e; c) Inclusión.

Como a seguir explicaremos, esos tres principios incluyen aquellos prescritos en el art. 206 de la Constitución Federal brasileña, por ejemplo: a) igualdad de condiciones para el acceso y permanencia en la escuela; b) libertad de aprender, enseñar, investigar y divulgar el pensamiento, el arte y el saber; c) pluralismo de ideas y de concepciones pedagógicas, y coexistencia de instituciones públicas y privadas de enseñanza; d) gratuidad de la enseñanza pública en estabelecimientos oficiales; e) gestión democrática de la enseñanza pública, en la forma de la ley; f) garantía de patrón de cualidad. Veamos.

a) Justicia

Al efecto del presente estudio presentamos la justicia como un principio que nos permite vincular la Educación, la moral y el Derecho, por incluir otros importantes sub-principios: Ciudadanía, Dignidad, moralidad, legalidad, convivencia, respeto, etc., y cuya complitud estriba la "igualdad equitativa de oportunidad"22 por medio de la cual ha de ser realizada una justa y equilibrada distribución del Derecho a la Educación para todas las personas, independientemente de sus planes personales de vida o de sus concepciones de bien.

Si queremos saber si una sociedad es justa, basta preguntar como ella distribuye las cosas que valorizan - renta y riqueza, deberes y derecho, poderes y oportunidades. En el plano educacional, una sociedad justa distribuye esos constructos de manera que posibilita oportunidades a cada individuo. Debemos observar que actualmente, la mayoría de las discusiones sobre justicia se da al respecto de cómo definir y concretizar los derechos de los ciudadanos. En ese sentido, predominan las consideraciones sobre el bienestar y la libertad. ${ }^{23}$

La justicia, en su dimensión socio-educacional ha de ser considerada como el primer principio a ser observado por el Estado, la familia y las instituciones sociales que, efectivamente, organizan la mejor manera de promover una igualdad de oportunidades. Decimos, entonces, que socialmente importa no solamente la igualdad formal,

\footnotetext{
21 ARAÑA, Maria Lúcia de Arruda. História da Educação. 2. ed. São Paulo: Moderna, 1996, p. 15 e 76.

22 OLIVEIRA, Nythamar de. Rawls. Rio de Janeiro: Jorge Zahar Ed, 2003, p. 17-18.

23 SANDEL, Michael J. Justiça - O que é fazer a coisa certa. Trad. de Heloisa Matias e Maria Alice Máximo. 10. ed. Rio de Janeiro: Civilização Brasileira, 2013, p. 20, 28.
} 
pero también la material. ${ }^{24}$ No promover esa forma de justicia es negar el desarrollo social (la probidad y la prosperidad).

Así, la justicia, en este contexto, significa "respetar ciertos derechos humanos universales". Esa concepción de justicia requiere que se corrijan las desventajas sociales y económicas y que den a todos, oportunidades justas de suceso. ${ }^{25}$

Entre las formas principales de justicia conocidas, en el ámbito educacional, importa destacar la justicia conmutativa, la distributiva y la legal. Así, como enseña Paulo Cesar $^{26}$, la justicia conmutativa, envuelve la relación entre los ciudadanos, garantizando a cada uno lo que es suyo, la distributiva, se refiere a la relación entre el Estado y el ciudadano, en que se asegura a cada uno lo que le cabe, y la justicia legal, que formaliza la relación entre el ciudadano y el Estado, donde se da al Estado lo que a él se debe. Tales formas de justicia se correlacionan dialécticamente en defensa de la Dignidad de la persona humana.

En la esfera educacional, la justicia conmutativa no es respetada por la constante agresión a los valores sociales, como medio, por ejemplo, de la publicidad abusiva que, cuando estimulada por el lucro, disemina mentiras y violencia; la distributiva no se efectiva por causa de la exclusión social, discriminación, corrupción, abuso de poder y la legal por la negación del Derecho a la Educación consagrada en la legislación vigente. En la ética de Aristóteles el concepto "injusto" se aplica tanto a las personas que infringen la ley como a las personas ambiciosas (en el sentido de querer más que aquello a lo que se tienen derecho), de tal forma que obviamente las personas cumplidoras de la ley y las personas correctas serán justas. Lo justo, entonces, es aquello que es de acuerdo a la ley (correcto), y lo injusto es lo ilegal e inicuo. ${ }^{27}$

Por tanto, no basta el reconocimiento formal del Derecho a la Educación, importa también su efectividad: no es con prescripción, mas con conciencia que se llega a la justicia.

Como explica el profesor José Roberto Goldim ${ }^{28}$ la justicia es un principio moral, Así, cabría preguntar: ¿quién debe recibir los beneficios que se derivan del Derecho a la

\footnotetext{
24 Igualdad formal. Se trata del vínculo de igualdad deseado entre individuos y grupos sociales, que es reconocido formalmente en las leyes vigentes, por medio de categorías abstractas, tales como, inclusión, Ciudadanía, Dignidad de la persona humana, etc. Igualdad material. Se trata de un vínculo de igualdad a ser establecido entre individuos y grupos sociales, como consecuencia de la implementación de políticas y condiciones concretas, que aseguren a cada ciudadano la plena satisfacción de sus necesidades.

25 SANDEL, Michael J. Justiça - O que é fazer a coisa certa. Trad. de Heloisa Matias e Maria Alice Máximo. 10. ed. Rio de Janeiro: Civilização Brasileira, 2013, p. 29.

26 SILVA, Paulo Cesar da. Os valores fundamentais e o Biodireito. In: RAMPAZZO, Lino; SILVA, Paulo Cesar da (Orgs.). Pessoa, Justiça Social e Bioética. Campinas: Alínea, 2009, p. 103.

27 ARISTÓTELES. Ética a Nicômacos. 2. ed. Trad. de Mário da Gama Kury. Brasília: Universidade de Brasília, c 1985, 1992, p. 91-92.

28 Principio de Justicia. Disponible en: <http://www.ufrgs.br/bioetica/justica.htm>. Accesso en: 21 jul. 2010.
} 
Educación? Esa es la esencia de la justicia: "distribución justa". Así, hay injusticia cuando el Derecho a la Educación es negado sin una buena razón.

Claramente, género, raza, creencia, nacionalidad, status social, etc. no pueden ser usados como criterios para la distribución de los bienes que la sociedad produce, ni para la oferta de oportunidades educacionales. ${ }^{29}$ Admitamos, pues, que cuando hablamos en justicia en el ámbito educacional también hablamos en igualdad de proporcionalidad.

Resumiendo, razonamiento sobre justicia es razonar a partir del telos o de la naturaleza del bien (Educación) en cuestión. Para concebir un orden (sistema educacional) justo, debemos reflexionar acerca de la naturaleza de la vida buena. No podemos elaborar una Constitución justa hasta no haber concebimos la mejor forma de vivir. ${ }^{30}$

\section{b) Integridad}

La palabra integridad es de origen latina (integritas), íntegro, completo, y sugiere la totalidad de los factores que conforman y complementan la Educación.

La Educación íntegra aquí será significada como un tipo de Educación (o proceso) que, independientemente de la instrucción, considera también importante la edificación de la conciencia social: jurídica y moral.

En ese sentido, la Educación integral es aquella que se reproduce no únicamente con base en una concepción limitada o restricta al desarrollo de la capacidad física e intelectual del ser humano, esta es, orientada sólo a la preparación del hombre para la vida, para el éxito profesional.

La Educación integral contempla el pluralismo de ideas y de concepciones pedagógicas, en el marco de la coexistencia de instituciones públicas y privadas de enseñanza compelidas a garantizar una Educación de calidad.

El principio de la integridad supera la idea de la instrucción para tomar de la moral y del Derecho, los indicadores importantes a ser introducidos en el proceso de enseñanza-aprendizaje. Al respecto de ese principio educacional, estudios históricos revelan su importancia y perspectiva ya indicada en la introducción a la presente obra: "Educar para no punir", orientación de la cual podemos inferir que el proceso de enseñanza-aprendizaje y la Educación en General deben ser orientados con base en los valores morales y en los principios jurídicos que organizan la conducta (el comportamiento) que la sociedad espera.

En conformidad con eso, decimos entonces que las diversas reflexiones acerca de la correlación entre la Educación, moral y el Derecho exige un componente vital que siempre importaron a las tradiciones filosóficas conocidas: China, Grecia, Índia, Europa medieval y moderna, todas ellas levantaron cuestiones éticas básicas, tales como: ¿Qué

29 DALL' AGNOL, Darlei. Bioética. Rio de Janeiro: Jorge Zahar Ed., 2005, p. 24-25.

30 SANDEL, Michael J. Justiça - O que é fazer a coisa certa. Trad. de Heloisa Matias e Maria Alice Máximo. 10. ed. Rio de Janeiro: Civilização Brasileira, 2013, p. 269. 
conducta debe ser considerada buena? ¿En qué consiste una vida virtuosa? ¿Cuáles son las virtudes del ser humano? ¿Existe un esquema bueno o un esquema unificado de virtudes? ¿Cuáles son los deberes de uno en relación a los otros? etc. En el mismo sentido, ¿Cómo la Ética y el Derecho pueden contribuir para la Educación? Esta es una cuestión que, igualmente, preocupa a los educadores, juristas y eticistas. Así, por ejemplo, cuestiones de Ética Profesional: en los negocios, en la medicina, en la abogacía, etc. poseen igualmente papel dominante, con base en la naturaleza de la profesión, en su lugar en la vida social y en la consecuente aplicación de principios éticos generales. ${ }^{31}$

Consideramos, pues, que la conjugación necesaria entre la Educación, la moral y el Derecho nos permite hablar de la Educación Integral como una obligación del Estado, como un Derecho humano necesario a la convivencia.

Actualmente preocupan, por ejemplo, la falta de eficiencia del poder público ante el aumento de la violencia, de la ilegalidad, de la corrupción, etc. Así, se discuten, sin mucho éxito, diversas formas para inhibir el uso indebido del poder público: el desvío de los recursos y de la riqueza nacional, la criminalidad, pensándose únicamente en el aumento de la sanción o en la diminución de la edad penal.

Importa, Así, difundir, por medio de la Educación, lo que es conveniente para la colectividad, a partir de un modelo educacional basado en el carácter racional de los fines, de los valores y de las prescripciones. Se trata, pues, de un modelo compatible con la propia búsqueda razonable del "bien común", es precisamente por esto que tales ciencias sociales abarcan la conducta de los individuos como miembros de una sociedad. $^{32}$

En ese sentido, la Educación integral es orientadora de nuestras acciones tanto de las personas comunes como de los futuros agentes que dirigirían las instituciones públicas y privadas, una Educación que procura preparar al hombre para la resolución de dilemas jurídicos y morales, generalmente nacidos del confronto de intereses individuales y colectivos, una Educación también universal (común a todos), aplicable a todo, lo que conviene para todos.

Esta es nuestra tesis principal: El ser humano es un ser libre, mas su libertad encuentra límites en la propia naturaleza y en la convivencia social. Los límites son ateridos por la razón, mas acatados por la consciencia. Así, la probidad del ser humano depende de la razón y de la conciencia siendo que, las normas sociales: jurídicas y morales entran en juego cuando tales límites no son respetados. Más allá de la crítica existe una cosa sobre la cual podemos llegar a un consenso: la Educación difunde los valores y disemina sus límites y, por tanto, es necesaria para la convivencia.

31 SKORUPSKI, John. Ética. In: BUNNIN, Nicholas; E.P. Tsui-James (Orgs). Compêndio de Filosofia. São Paulo: Loyola, 2002. p. 197-198.

32 VILLORIA Mendieta, Manuel. Ética pública y corrupción: Curso de ética administrativa. Madrid: Tecnos, 2000, p. 18. 
Varias son las razones de este segundo principio. Se trata de una orientación que, cuando observada, va a servir para la convivencia humana, esto es, al buen desempeño y a la probidad de los juristas, de los políticos, de los administradores, de los empresarios, etc., pues incide directa e indirectamente en la preparación del ser humano para la comprensión y la resolución de problemas sociales, tales como: a) las violaciones de los Derechos humanos; b) la informalidad y la violencia; c) los conflictos bélicos; d) la exclusión social; e) el desarrollo social; f) la agresión ambiental y, en fin, la desobediencia social.

c) Inclusión

La Educación, ya explicamos, es un proceso de todos y para todos, esto es, un Derecho del hombre. Hablamos de aquella Educación que ha de alcanzar a todos los ciudadanos, pues se proyecta para todos los individuos, para todo ser humano.

Hablamos ahora de una Educación que llega para incluir a todos en la senda del desarrollo social y humano. La Educación no inclusiva contribuye para el aumento de las desigualdades y de la injusticia, problemas que indican la disminución de la dimensión humana y que también es objeto de nuestro interés científico.

\section{CONCLUSIÓN}

Podemos concluir que la Educación, a partir de sus dos niveles o dimensiones. El primero, aquel que se refiere a la Educación escolar, donde se desarrolla un proceso educacional preconcebido y organizado y, el segundo, el que se refiere a las políticas educacionales que incluye las instituciones públicas, privadas y la comunidad en General (familia, sociedad y Estado). Mas, en este trabajo importa discutir como la escuela puede vivenciar y traducirse en acciones (en prácticas) un proyecto que permita internalizar los valores con el objetivo de edificar la consciencia social, o sea, demostrar como las políticas educacionales de un país o de un gobierno contribuye para la realización de esos valores. ${ }^{33}$ Debido a la importancia de los principios, a seguir, discutiremos sus significados.

Hemos de observar que el principio de la inclusión envuelve la gratuidad de la educación (enseñanza) pública en establecimientos oficiales y su gestión democrática conforme a la ley. Por esa razón, es necesario dar una oportunidad a aquellos jóvenes que no pueden disfrutar de tales condiciones y que precisan de orientación para la formación y desarrollo de sus habilidades y talento.

La Educación no inclusiva es de hecho, la causa del aumento de la violencia, de la ilegalidad, de la inmoralidad, de la corrupción. Por causa de ella, la democracia y la ciudadanía pierden sus razones al ser quebrados los criterios en los cuales se basa su

33 GOMES, Cândido Alberto. Dos Valores Proclamados aos Valores Vividos. Brasília: UNESCO, 2001, p. 101. 
funcionamiento, dificultándose la comprensión de las políticas existentes, de sus alternativas y consecuencias posibles.

Así, "facilitar el acceso a la Educación, a estudiar y a profesionalizarse son desafíos de la educación moderna, en el sentido de superar las condiciones precarias de la enseñanza, la desigualdad en la distribución de oportunidades, formación insuficiente, bajos salarios, falta de recursos y la no determinación de las prioridades nacionales".34

Los desafíos que, los procesos educativos, imprime a la dinámica de la vida moderna alertan acerca de la necesidad de repensar los conceptos de la Educación tradicional e idealizar una Educación que permita la realización de la Ciudadanía. Pasaremos, así, en la presente sección, a considerar que la no efectuación de la Educación inclusiva puede incidir en la no concretización de los Derechos Humanos y Fundamentales y, consecuentemente, en la no realización de la ciudadanía en los contextos socioeconómicos y jurídicos contemporáneos.

En suma, la función de los principios, así concebidos, es la de contribuir para un modelo crítico que permita juzgar el sistema educacional de una sociedad de cara a la adecuada concretización del derecho a la educación, aquí concebido como el "bien primario" de los individuos que conviven y cooperan en una sociedad democrática. ${ }^{35}$ La utilidad de los principios propuestos gira en torno de tres objetivos: aumentar el bienestar, respetar la dignidad y promover la conciencia.

\section{REFERENCIAS}

ARAÑA, Maria Lúcia de Arruda. História da Educação. 2. ed. São Paulo: Moderna, 1996.

ARISTÓTELES. Ética a Nicômacos. 2. ed. Trad. de Mário da Gama Kury. Brasília: Universidade de Brasília, c 1985, 1992.

BARBAROSCH, Eduardo. Teorías de la Justicia y la Metaética Contemporánea. Buenos Aires: La Ley; Facultad de Derecho y Ciencias Sociales - Departamento de Publicación, 2011.

BAUMAN, Zygmunt. Sobre Educação e juventude: conversas com Ricardo Mazzeo. Trad. Carlos Alberto Medeiros. Rio de Janeiro: Zahar, 2013.

BOBBIO, Norberto. A Era dos Direitos. Trad. Carlos Nelson Coutiño. Rio de Janeiro: Elsevier, 2004.

CUNNINGHAM, Willian Francis. Introdução à Educação: Problemas fundamentais, finalidades e técnicas. 2. ed. Porto Alegre: Globo, 1975.

DALL'AGNOL, Darlei. Bioética. Rio de Janeiro: Jorge Zahar Ed., 2005.

34 SEVERINO, António Joaquim. Filosofia da Educação: construindo a Cidadania. São Paulo: FTD, 1994. (Apresentação)

35 BARBAROSCH, Eduardo. Teorías de la Justicia y la Metaética Contemporánea. Buenos Aires: La Ley; Facultad de Derecho y Ciencias Sociales - Departamento de Publicación, 2011, p 12-13. 
DALLARI, Dalmo de Abreu. Direitos humanos e Ciudadania. São Paulo: Moderna, 1998.

DEWEY, John. Vida e Educação. 10. ed. São Paulo: Melhoramentos, 1978.

DÍAZ Bordenave, Juan e Martins Pereira, Adair. Estratégias do ensino aprendizagem. 14. ed. Petrópolis: Vozes, [s.d.].

DURKHEIM, Émile. Educação e Sociología. Trad. de Stephania Matousek. 3. ed. Petrópolis, RJ: Vozes, 2012.

GAGNÉ, Robert. Como se realiza a aprendizagem. Trad. Thereziña Maria Ramos Tovar. Rio de Janeiro: Livros Técnicos e Científicos Editora S. A / MEC. [s.d]

GIUSEPPE Imídeo Nérici. Metodologia do ensino. Uma introdução. 4. ed. São Paulo: ATLAS, 1992.

GOMES, Cândido Alberto. Dos Valores Proclamados aos Valores Vividos. Brasília: UNESCO, 2001.

OLIVEIRA, Nythamar de. Rawls. Rio de Janeiro: Jorge Zahar Ed, 2003.

SANDEL, Michael J. Justiça - O que é fazer a coisa certa. Trad. de Heloisa Matias e Maria Alice Máximo. 10. ed. Rio de Janeiro: Civilização Brasileira, 2013.

SEVERINO, António Joaquim. Filosofia da Educação: construindo a Cidadania. São Paulo: FTD, 1994.

SILVA, Paulo Cesar da. Os valores fundamentais e o Biodireito. In: RAMPAZZO, Lino; SILVA, Paulo Cesar da (Orgs.). Pessoa, Justiça Social e Bioética. Campinas: Alínea, 2009.

SKORUPSKI, John. Ética. In: BUNNIN, Nicholas; E.P. Tsui-James (Orgs). Compêndio de Filosofia. São Paulo: Loyola, 2002.

VILLORIA Mendieta, Manuel. Ética pública y corrupción: Curso de ética administrativa. Madrid: Tecnos, 2000, p. 18. 